\title{
Conception and Development of a Last Mile Vehicle for Urban Areas
}

\author{
Andreas Höfer, Erhard Esl, Daniel Türk, and Veronika Hüttinger
}

\begin{abstract}
In megacities, increasing globalization effects are leading to rapidly increasing prosperity and augmented purchasing power, and thus to a growing need for punctual, cost-effective, and environmentally friendly delivery of goods. A smart, small electric vehicle concept is presented that targets on meeting the requirements for the delivery of goods in urban areas and that is designed especially for the delivery on the last mile. This last mile vehicle (LMV) for cargo transportation is attached to a truck. Whenever it is needed, for example to deliver goods into narrow streets, in pedestrian areas or in case of traffic jams, it can be unfolded and unloaded from the truck and hereby guarantees a flexible and punctual delivery of goods. This flexible on-time delivery is possible because the last mile vehicle is designed, so that the legal regulations of the non-motorized vehicle lane, that is everywhere to be found in Asia, are met. The vehicle is designed with three wheels, a range of $40-60 \mathrm{~km}$ and an electric drive train with a continuous power of $2 \times 250 \mathrm{~W}$ that enables a maximum speed up to $40 \mathrm{~km} / \mathrm{h}$ of the vehicle. The drive train consists of a battery pack that can be charged electrically from the truck, two inverters, and two electric wheel hub motors. The LMV has been designed and constructed as a prototype and has been tested on non-public roads to prove the vehicle concept. For Europe, it can be classified as an L2e vehicle and with slight modifications; it can be applied on European roads as well.
\end{abstract}

Keywords Last mile vehicle - Small electric vehicle - Smart mobility • Connected car

A. Höfer $(\bowtie) \cdot$ E. Esl · D. Türk · V. Hüttinger

Technical University of Munich (TUM), Boltzmannstr. 15,

85748 Garching bei München, Germany

e-mail: hoefer.andy@gmail.com

(C) The Author(s) 2021

A. Ewert et al. (eds.), Small Electric Vehicles,

https://doi.org/10.1007/978-3-030-65843-4_13 


\section{Introduction}

In China, there is an old saying: “要致富先修路” (loosely translated: If you want to be rich, you must first build roads) [1]. Especially in Chinese megacities, this wisdom has been put into effect for quite some time, leading to prosperity in the ever-increasing middle class and to urban infrastructures that have reached their maximum of capacity in many places. Nevertheless, the urbanization continues (e.g. Shanghai had a population growth of $38 \%$ in the years from 2000 to 2011 [2]) and studies predict that by 2030 , one billion people will be living in urban areas in China. This will produce a tenfold increase of the traffic volume [3]. The high population density, as well as the population's desire for motorized transport, is leading to the well-known megacity problems such as harmful emissions, smog, and sustained traffic congestion. Electrification, car-sharing, and an expansion of public transportation provide the first solutions for passenger transportation. However, few alternative solutions have been developed so far for the transportation of cargo, although the demand for an on-time delivery of the goods to the final customers continues to grow in importance [4]. Public access to the Internet and the associated introduction of e-commerce accelerates the development of rising freight flows. This brings great challenges to logistics companies especially for the last mile delivery stage [4]. The last mile is the final delivery stage in the logistics chain in which the goods reach (final) customers. Here, the cargo has to be delivered on time in the densest neighborhoods, via narrow one-way streets, into the historic city centers or into pedestrian areas to different customers. Thus, the last mile is not only the bottleneck of the delivery chain, but also provides the largest potential for innovative vehicle concepts and mobility solutions.

\section{Methodical Approach}

When developing vehicles for cargo transportation, one has to start with the transport task including its customer and market-specific requirements [5]. For this purpose, a market analysis was carried out for the example of Shanghai to understand the logistics chain in Asian megacities (Fig. 1, step 1). The analysis included, among other aspects, expert interviews, traffic flow observations or visits to various logistics centers (details of the market analysis compare [6, 7]). From this, explicit product requirements could be derived such as the length of the last mile or transport volumes and masses (Fig. 1, step 2). Along with the legal regulations as well as the customer's needs, as determined by surveys among truck drivers, a list of requirements for specific vehicle concepts for the last mile is derived. This list of requirements was the basis for subsequent methodical concept development and concept evaluation using product development methods from [6] such as the morphological method (Fig. 1, step 3). The most suitable concept was then further detailed using CAD methods for design and simulation (Fig. 1, step 4). Finally, a 


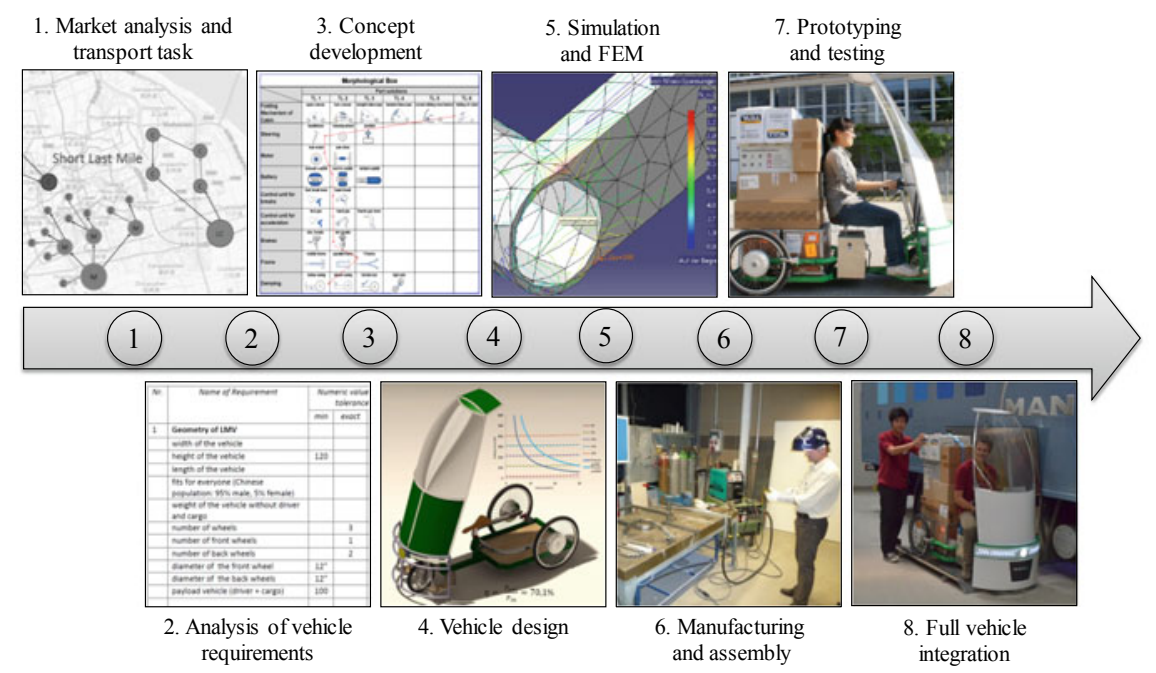

Fig. 1 Product development process for the development of a cargo vehicle for urban areas starting from the definition of the transportation task (step 1) leading to the prototyping and testing (step 7) as well as to the overall vehicle integration (step 8)

prototype of the vehicle concept was manufactured, assembled, and tested (Fig. 1, steps 5-8). A special characteristic of the developed vehicle is its integration into the truck, which greatly affects the system boundary conditions for the design and construction. For example, the ground clearance of the truck has to be kept, which may restrict the available space for stowage of the last mile vehicle (LMV). On the other hand, the integration opened new degrees of freedom such as the connection of the LMV to the $24 \mathrm{~V}$ electrical system of the truck.

The applied product development methodology for last mile delivery vehicles is shown in Fig. 1.

\section{Field Study, Use Cases, and Vehicle Requirements}

In Shanghai, a substantial distinction can be made between four different logistic situations [6]. These can be seen in Fig. 2. Logistic situation 1 (Fig. 2, top left) is the original form of goods transportation in China. Truck drivers, working on a freelance basis with small delivery trucks, wait for orders at collection points near large urban thoroughfares. One delivery journey is to pick up the goods at a place X and deliver them to the final customer $\mathrm{C}$. Afterward, the driver returns to the starting point. This entails low capacity utilization and many empty journeys. The last mile is the total distance traveled by the delivery truck; in this case, it is up to $40 \mathrm{~km}$. The transport of foods, described by logistics situation 2 (Fig. 2, bottom left), is based on a multi-level market system via which the goods are moved to the 


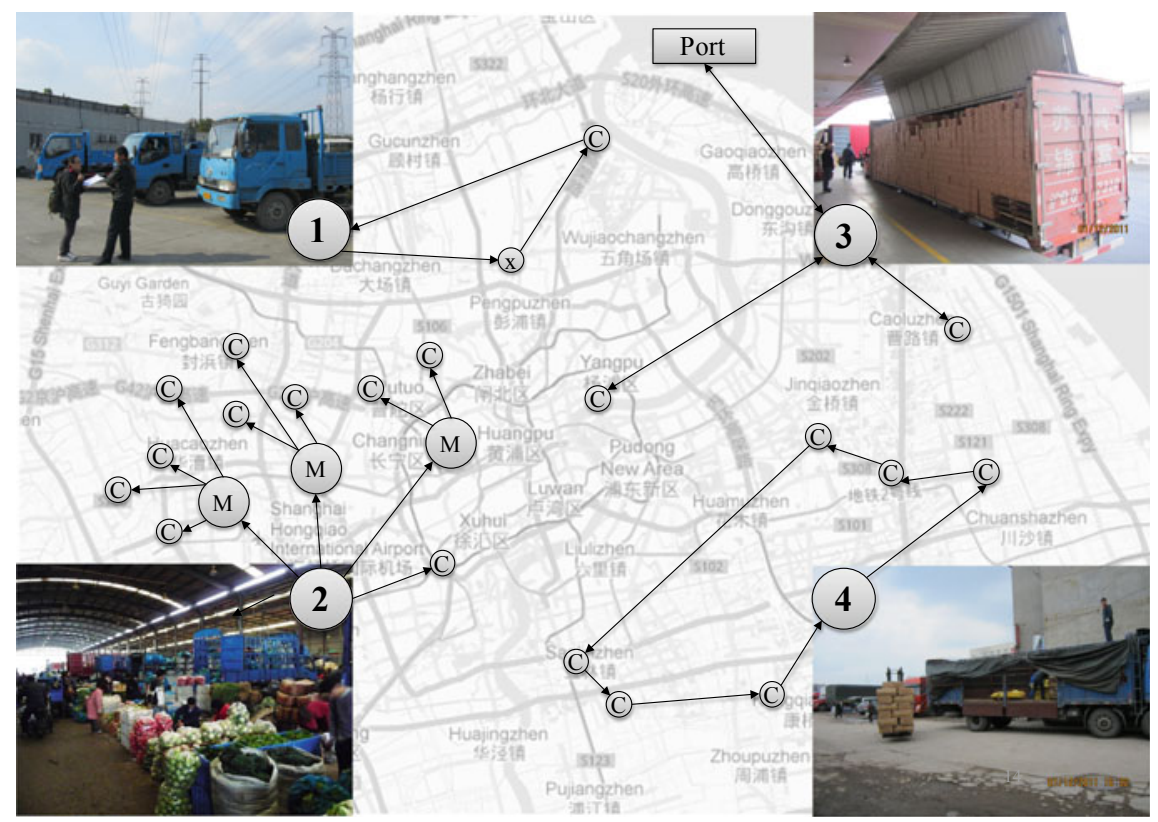

Fig. 2 Description of the different cargo delivery situations that can be found in Chinese megacities today

end customer C. Here, the goods are transported over a last mile that is only up to $2 \mathrm{~km}$. This last mile often includes transportation in pedestrian areas or in the tight confines of the historical city center. Modern transport logistics structures can also be found in Shanghai (Fig. 2, top right and bottom right) and follow the principle mega hubs in megacities, which is further described in [4].

In this case, the delivery takes place on optimized routes that are driven along either on a direct route or a star-shaped route, depending on the number of identical goods, volume, and location of the end user. Thus, the distance of the last mile varies between 20 and $80 \mathrm{~km}$ depending on type of route. The market analysis yields a required minimum range for the LMV of $R_{\min }=40 \mathrm{~km}$ [6]. This way three of the four logistics situations can be served.

Other important vehicle concept requirements are presented qualitatively in Fig. 3 and are quantified in [7]. The requirements are brought together from six different fields of research. Those include the legal requirements, the requirements to the transportation task (compare Fig. 2) especially on the last mile, urban structures of megacities, the interfaces to the delivery truck, and finally the ergonomic aspects and desires of truck drivers (compare [7]).

Exemplarily two requirements (compare [7]) are further quantified: The need for high vehicle agility results in the requirement of the small turning radius of $r=1.25 \mathrm{~m}$. The minimum load capacity in volume should be $V_{\text {load }}=1 \mathrm{~m}^{3}$ and $m_{\mathrm{load}}=80 \mathrm{~kg}$ in mass [7]. 


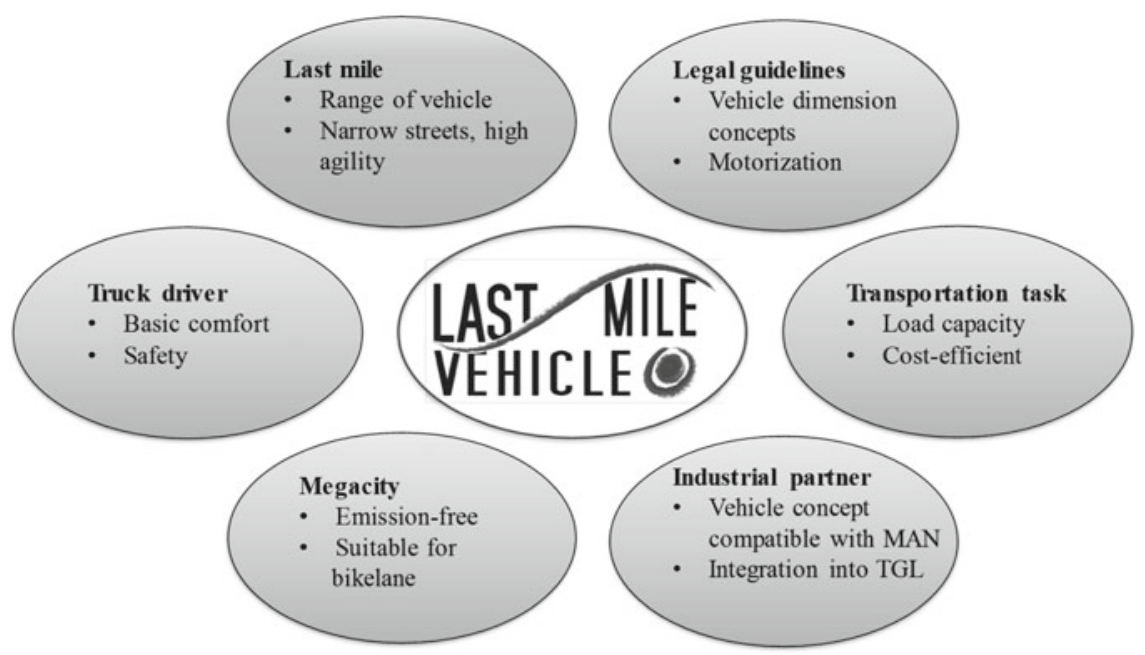

Fig. 3 Key vehicle requirements derived from six fields of research

In addition, the survey carried out with Chinese truck drivers resulted in the need for the provision of basic comforts such as protection against bad weather and the desire for greater active and passive safety measures. A special feature of the LMV is the conceptual design and suitability for bike lanes, which can be found all over metropolitan Shanghai. This hybrid solution increases flexibility for a timelier delivery of goods. The bike lanes are less often affected by traffic jams and traffic obstructions than the main roads. Thus, a flexible on-time delivery of goods is mostly possible. The hybrid design of the LMV for both main roads as well as bike lanes leads to various specific requirements. For example, the requirements for the bike lane bring legal restrictions to the vehicle design such as the number of wheels or the drive concept. Regarding the drive, combustion-powered vehicles are not allowed, whereas electrified vehicles with limited maximum power are permissible.

\section{Draft Designs, Evaluation, and Conceptual Component Design}

Using diverse creativity techniques from [8] such as brainstorming or the "6-3-5" method, innovative concepts could be developed and systematically structured with morphological boxes. Finally, the concepts were evaluated with a benefit analysis. In Fig. 4, six selected design sketches of vehicle concepts for the last mile that were developed are shown.

Consequently, the six design ideas and their advantages are shortly described. The "Roadrunner" concept is a further development of a Segway ${ }^{\text {TM }}$ designed for the 


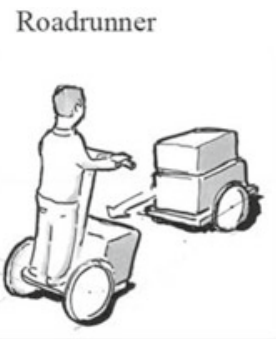

E4W

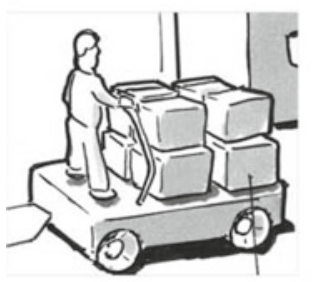

TUC - Bike

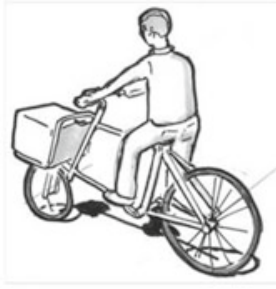

MiniMAN

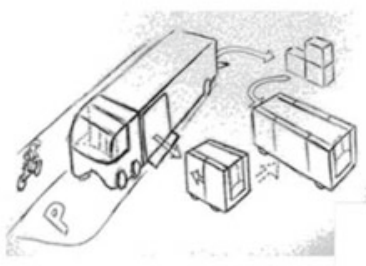

Smartwheeler

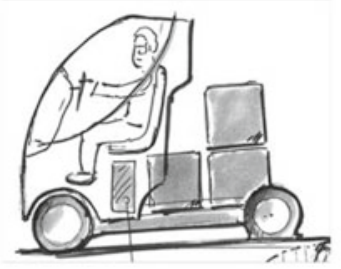

MoBo

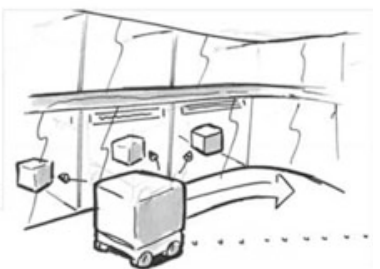

Fig. 4 Visualization of six different small electric vehicle concept for the last mile delivery

transportation of cargo. The vehicle concept shown here is modular and expandable at the same time, allowing multiple units of goods to be transported. The "TUC-Bike" concept is a cargo bike based on a pedelec. In contrast to many state-of-the-art pedelecs (see [8]), a folding mechanism was planned. As a consequence, the bike can be carried on a truck in a space-saving way. The cargo area is extendable and adaptable to the packet size. The "Smart Wheeler" is a four-wheeled electric vehicle that has an enclosed driver cabin. This cabin protects the driver from environmental influences. The cargo is placed behind the driver, and the electric energy storage devices are placed beneath the driver's seat. Thus, a low center of gravity for the vehicle is realized. The "E4W" is considered to be a cuboid vehicle concept that focuses on maximizing payload. The cuboid includes all drive components and the energy storage devices. As a consequence of the compact design, space-saving stowage on the ladder frame beneath the truck is possible. This enables a quick setup of the vehicle and requires no load volume due to the position beneath the superstructure of the truck. The conceptual idea of "MiniMAN" is to divide the loading space of a $7.5 \mathrm{t}$ truck into several modular units. On these modular units, the cargo is already pre-consolidated. Furthermore, these modular units contain their own drivetrain and storage components and thus can act as an independent, small electrical supply truck on the last mile into downtown, while the 7.5t truck waits at the edge of town. The "Mobo" concept is related to the "MiniMAN" concept. In contrast, the modular units will drive autonomously. Furthermore, the vehicle units have standardized sizes, such as the size of one 
euro-pallet. These pallet-sized vehicle concepts deliver the goods to the end customers without a driver and thereby shuttle multiple times between customers and truck.

\section{Prototyping}

\subsection{Vehicle Design and Characteristics}

Based on a Chinese tricycle, the MANgo concept was implemented in the form of a functional prototype (Fig. 5a) as it was evaluated the highest in the concept evaluation phase (further details to the value benefit analysis can be found in [7]). Being a purely electrically driven three-wheeled vehicle, it is designed, so that it is suitable for bike lanes in Asia. To be able to drive within urban traffic flow on major roads, the vehicle is equipped with two wheel hub motors with a combined electric peak power of $P_{\max }=2 \times 250 \mathrm{~W}$ and a maximum torque of $M_{\max }=2 \times 40 \mathrm{Nm}$. This enables a maximum velocity up to $v_{\max }=40 \mathrm{~km} / \mathrm{h}$. For the wheel hub motors, brushless direct current (BLDC) motors with external rotors are used. The motors are held with spokes directly inside the middle of the wheel (Fig. 5b). The spokes and tires thus have a resilient effect and thereby protect the drive against impacts, which has a positive effect on the lifetime of the electrical machine. The two energy storage units are placed under the driver's seat (Fig. 5c). Their capacity of $0.5 \mathrm{kWh}$ results in a range of $40-60 \mathrm{~km}$ for the vehicle. The powertrain has an intentionally redundant structure in order to compensate failures (Fig. 5d). The suspension is designed as a semi-rigid axle (Fig. 5e) and can even ride on curbs. One special technical feature is the attachment of the pushrod actuated air springing/damper units in a space-saving horizontal orientation. The torsional rigidity of the rear axle is designed, so that the wheels can deflect independently from each other. The stator of the wheel hub motor functions as an integrated wheel carrier. Furthermore, Fig. 5c shows the front wheel assembly including a disk break. Figure 5d shows the folding mechanism to convert the vehicle to the folded state [7].

The main technical data of the vehicle is summarized in Table 1 below.

\subsection{Key Characteristic - Vehicle Integration}

A special feature of the MANgo is the driver cabin that is foldable and protects the driver from environmental influences. Thus, compared to conventional tricycles, the cabin boasts greatly improved comfort. Due to the folding mechanism of the cabin, the vehicle can be stowed in a box carried underneath the body of the truck (Fig. 6; steps 1 and 2). 

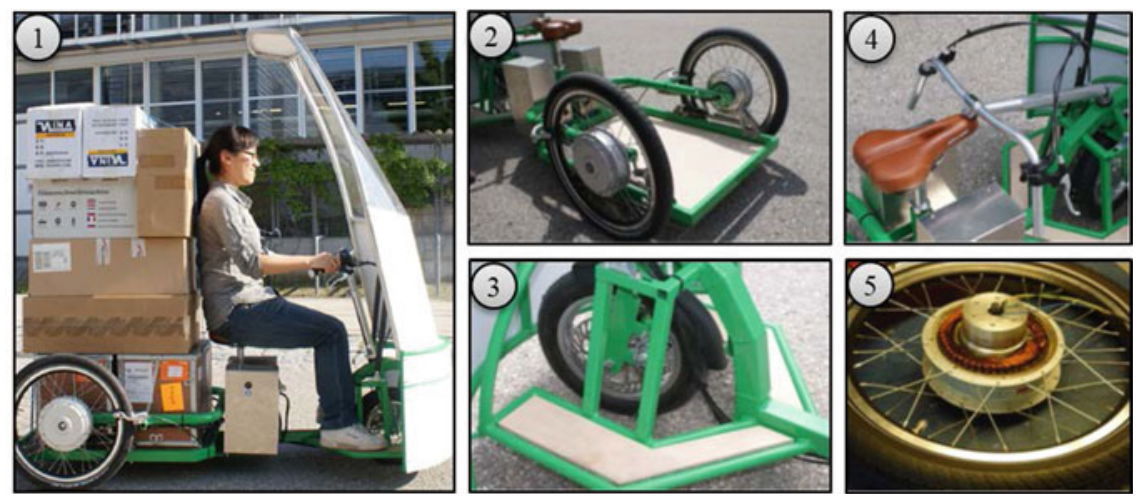

Fig. 5 1. Overall vehicle view; 2. Rear part and cargo area; 3. Front part vehicle assembly; 4. Middle vehicle part incl. battery storage and handle bars (folded position); 5. BLDC wheel hub motor

Table 1 Technical key features of the vehicle concept

\begin{tabular}{l|l}
\hline Technical key features of the vehicle concept \\
\hline Diameter of the wheels $\boldsymbol{d}_{\text {front }} / \boldsymbol{d}_{\text {back }}$ & $13^{\text {“ }} / 19^{\text {“ }}$ \\
\hline Maximum velocity $\boldsymbol{v}_{\mathbf{m a x}}$ & $40 \mathrm{~km} / \mathrm{h}$ \\
\hline Maximum torque $\boldsymbol{M}_{\mathbf{m a x}}$ & $80 \mathrm{Nm}$ \\
\hline Maximum power $\boldsymbol{P}_{\mathbf{m a x}}$ & $500 \mathrm{~W}$ \\
\hline Dimensions in operational state (length $\times$ width $\times$ height) & $1.70 \mathrm{~m} \times 0.76 \mathrm{~m} \times 1.70 \mathrm{~m}$ \\
\hline Dimensions in transportation state (length $\times$ width $\times$ height) & $1.70 \mathrm{~m} \times 0.76 \mathrm{~m} \times 0.55 \mathrm{~m}$ \\
\hline Load capacity $\boldsymbol{V}_{\text {load }}$ & $1 \mathrm{~m}^{3}$ \\
\hline Maximum vehicle load capacity including driver $\boldsymbol{m}_{\mathbf{m a x}}$ & $200 \mathrm{~kg}$ \\
\hline Empty mass $\boldsymbol{m}_{\mathbf{0}}$ & $38 \mathrm{~kg}$ \\
\hline Vehicle range $\boldsymbol{R}$ & $40-60 \mathrm{~km}$ \\
\hline Ergonomics & $5 \%$ female, 95\% male \\
\hline Wheel base $\boldsymbol{l}$ & $1.22 \mathrm{~m}$ \\
\hline Maximum steering angle $\boldsymbol{\delta}$ & $35^{\circ}$ \\
\hline
\end{tabular}

This way the MANgo does not subtract any volume from the truck's loading space. The folding mechanism is equipped with two gas springs designed to assist the folding kinematics of the cabin [7].

The setup and the loading of the vehicle for the last mile can be done within $60 \mathrm{~s}$ (Fig. 6, step 3). To accomplish this, the MANgo is placed on a platform which also functions as the bottom plate of the storage box. The vehicle can be electrically lowered and raised with the help a spindle drive and two vertically laced linear guides mounted on the ladder frame. Using two horizontal linear guides, the vehicle can be pulled out from beneath the truck and then loaded with goods. 
Fig. 6 Truck integration and four step setup process

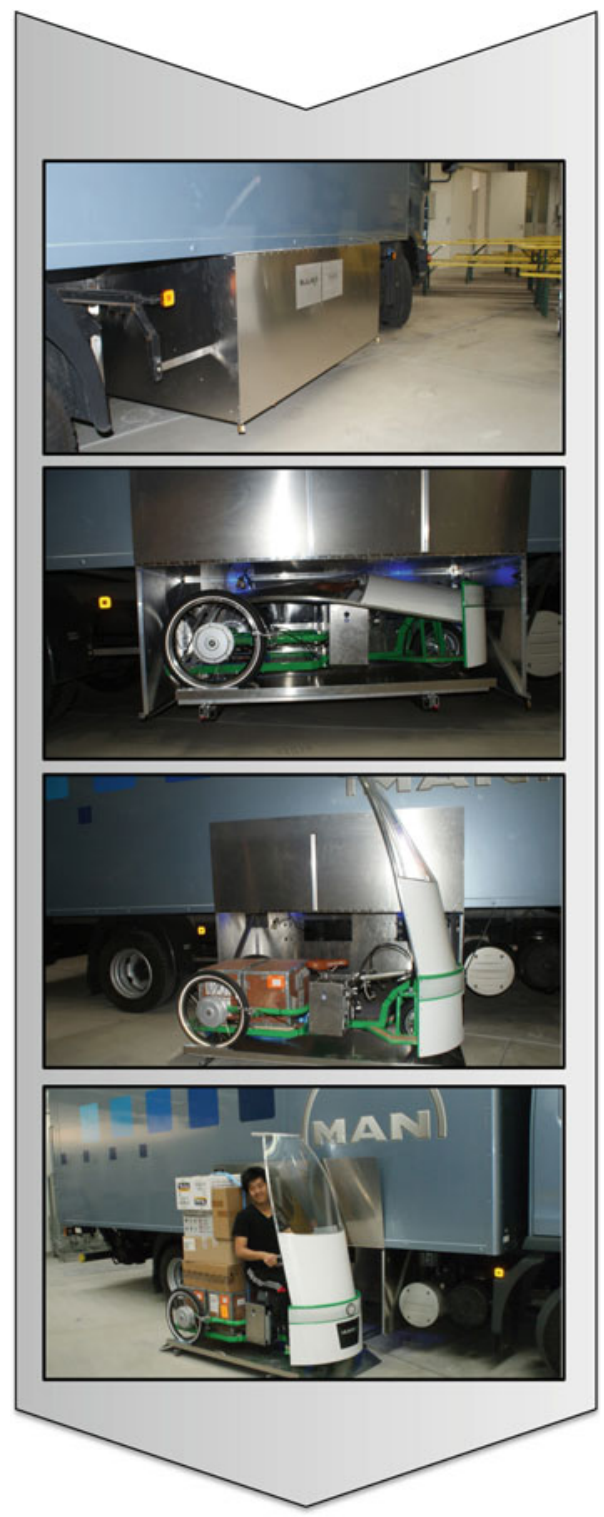

\section{Summary and Outlook}

New vehicle and mobility concepts are necessary to meet the increasing challenges of progressive urbanization. At the Technical University of Munich, these challenges were analyzed for cargo transportation and a design methodology for last mile vehicles was developed. For the example of Shanghai, the transportation task 
for goods delivery in megacities was analyzed, and innovative vehicle concepts were developed and evaluated methodically. The MANgo vehicle concept has been prototypically built and was able to meet all the functional requirements during the testing.

The MANgo that was awarded with a national scientific research award [9] is an electrified tricycle and thus is based on the tradition of Chinese three-wheeled cargo concepts. The foldable driver cabin and the vehicle's compact design allow it to be carried onboard commercial vehicles such as the MAN-TGL. The vehicle also meets the requirements for the use of bike lanes. The implemented technical innovations create a competitive advantage for the vehicle in a variety of different delivery scenarios. For example, in the case of a traffic jam, the MANgo can be unloaded and be set up within a minute. Prioritized goods are transshipped, and on-time delivery is assured. Bike lanes can be used, increasing flexibility and smart mobility. With its electric powertrain, the vehicle is also able to navigate inner cities and deliver into pedestrian areas and is suitable for the narrow streets in old city centers. A more futuristic delivery scenario involves several agile LMVs that are connected with each other and networked with a larger logistics vehicle traveling on outer ring roads. After delivery, the LMVs shuttle back multiple times to the heavy duty truck in order to pick up new loads.

Even though the MANgo has not passed from prototype stage to a serial release yet (2020) that new, small electric vehicle (SEV) concepts including new design methodologies are necessary not only for passenger transport but also for cargo transportation.

The future will show whether small zero-emission vehicles specially designed for the last mile will prevail in logistics in megacities, or if deliveries will continue with conventional large delivery trucks. However, if those conventional delivery trucks are stuck in traffic jams, the vehicle concept presented here for the last mile would still have the advantage of unlimited mobility.

Acknowledgements The scientific content of this paper are resulting from the global Drive Program at Technische Universität München, Lehrstuhl für Fahrzeugtechnik, Fakultät für Maschinenwesen (https://www.mw.tum.de/ftm/lehre/internationale-studentenprojekte/). Some parts were already published in [10].

The results were derived together with Tongji University and MAN Truck \& Bus SE. Special thanks to Dr. Britta Michel, Dr.-Ing. Frank Diermeyer, and Alexander Süßmann.

\section{References}

1. Biswas, A., Tortajada, C: Bridging the infrastructure deficit. In: The Business Times (2013)

2. Government-China: Infosite Goverment China, 1 July (1999). https://inquiryshanghai.weebly. com/population-characteristics.html, accessed 16 July 2020

3. Textor, M.: (w.Y.) Institut für Pädagogik und Zukunftsforschung (IPZF). http://www. zukunftsentwicklungen.de, accessed 21 January 2015

4. Deutsche Post AG: Delivering Tomorrow-Logistik 2050: Eine Szenariostudie. Deutsche Post AG, Bonn, Deutschland, ISBN 978-3-920269-53-5 (2012) 
5. Hoepke, E., Breuer. S.: Nutzfahrzeugtechnik, Köln und Weinheim: Vieweg + Teubner Verlag, Springer Fachmedien Wiesbaden GmbH (2010)

6. Esl, E., Höfer, A., Türk, D., Hüttinger, V.: Abschlusspräsentation: Last Mile Vehicle for Chinese Megacities, München: Technische Universität München, Designskizzen: Bram van Krieken, 24 May (2012)

7. Höfer, A.: Diplomarbeit: Conception and Development of a Last Mile Vehicle: From the Concept to the Prototype. Technische Universität München; Lehrstuhl für Fahrzeugtechnik, München (2012)

8. Lindemann, U.: Methodische Entwicklung technischer Produkte: Methoden flexibel und situationsgerecht anwenden, Garching: Springer. Heidelberg, London, New York, Dordrecht (2009)

9. IAV: Springer Professional: Hermann-Appel Preis für herausragende wissenschaftliche Leistungen in der Fahrzeugtechnik (2014). https://www.springerprofessional.de/automobilmotoren/iav-hermann-appel-preis-2014-verliehen/6585218. Accessed 28 April 2020

10. Höfer, A., Esl, E., Türk, D., et al.: Innovative Fahrzeugkonzepte für Shanghais letzte Meile. ATZ Automobiltech Z 117, 76-81 (2015). https://doi.org/10.1007/s35148-015-0049-y

Open Access This chapter is licensed under the terms of the Creative Commons Attribution 4.0 International License (http://creativecommons.org/licenses/by/4.0/), which permits use, sharing, adaptation, distribution and reproduction in any medium or format, as long as you give appropriate credit to the original author(s) and the source, provide a link to the Creative Commons license and indicate if changes were made.

The images or other third party material in this chapter are included in the chapter's Creative Commons license, unless indicated otherwise in a credit line to the material. If material is not included in the chapter's Creative Commons license and your intended use is not permitted by statutory regulation or exceeds the permitted use, you will need to obtain permission directly from the copyright holder. 